\title{
TEACHING LINGUISTIC TERMS IN MOTHER TONGUE CLASSES
}

\author{
Tajbenova Saule Sarsengalievna \\ Phd in pedagogy, Nukus state pedagogical institute named after Ajiniyaz, "Primary \\ education" department
}

\begin{abstract}
The article is devoted to the linguistic terminology teaching problems in native language classes of elementary school, teaching pupils to determine the levels and sections, as well as understanding the differences between language levels and linguistic phenomena.
\end{abstract}

Key words: term, definition, imagination, denotative model, lexical dictionary, denotative aspect, significative aspect, paradigmatic aspect, syntagmatic aspect, background aspect, empiricist aspect

\section{Introduction}

One of the theoretical knowledge elements in primary school mother tongue lessons is the effective work importance on the term, as a result of which pupils can rely on it, on the one hand, to memorize the language level, on the other hand, to find relevant topics in textbooks, and, most importantly, rules will be armed with an easy way to search. According to the methodologist M. Mirmakhsudova, "the grammatical term should be mastered by students at the level of distinguishing a linguistic phenomenon, knowing which linguistic phenomenon we are talking about by name." Only then can a grammatical term act as a bridge between linguistic phenomena and rules and definitions» [1]. It is therefore correct to consider the terms practical application as indirect. Pupils should learn to use this "bridge" both in finding the appropriate language level and in searching for a topic through textbook pages, more precisely and more conveniently, and acquire relevant knowledge, skills, and competencies. Once the topic is clear, a direct rule is opened.

\section{Main part}

Since the linguistic terms importance consists of the above, the work on them in a certain sequence should be organized in the same way. That is:

1) study the term, form a relevant concept;

2) formation of knowledge, skills, abilities on the term;

3) identify the topic covered in the textbook based on the term;

4) find the necessary rule based on the subject materials review.

In the primary grades, only in the 3rd grade do language levels begin to be distinguished. But in one of these textbooks there are fewer major levels, in another more. For example, in the 3rd grade textbook "Mother tongue" there are only three sections: "Speech", "Word structure", "Parts of speech" [2]. In the 4th grade «Mother tongue» textbook [3] «Parts of speech», «Noun - parts of speech», «Adjectives - parts of speech», «Numbers - parts of speech», «Personal pronouns», «Verb - parts of speech» sections are separated. Apparently, only in 4th grade is there a great chance of finding the right topic based on language levels.

After learning the term, a short pronunciation exercise is followed by an activity aimed at generating understanding. Concept is about meaning. Methodist scholar I.P. Slesareva explains the meaning of the word as follows: «Lexical meaning ... is understood as a knowledge system that relates its aspects to the general idea (concept) of the object, the visual-emotional representation of the object (imagination) and the diagram of the relationship between objects (denotative models)», « The sum of the lexical meanings is mutually conditioned. The word dictionary, as a unit of 'system', possesses all of these descriptions; in speech they are concretized, because a word calls something (denotative aspect), signifies something (signifier aspect), it is chosen from a group of words (paradigmatic aspect) and connected with other words (syntagmatic aspect), through which the speaker expresses a certain attitude to what is being said (pragmatic aspect), which reflects the specific knowledge of the speaker (background aspect) and the image of the subject (empirical aspect) [4]. The term, as a word, also refers to a set of meanings by grouping specific words. Among the meanings, the term reflects the word meanings and the word form that it represents in the abstract.

So, in the theoretical knowledge there will be a new or mastered term-concept: the term is either introduced for the first time and explained using a definition, or a linguistic phenomenon is explained based on it. Information about a language level also begins with naming the level. For example, phonetics, spelling. Descriptive and classification data are then provided. Because levels (phonetics, spelling, lexicology, morphology, etc.) are also classified according to the language structure. This is the first large grouping that elementary school pupils learn to a lesser extent.

Going from term to topic, from topic to rule, has its challenges. These difficulties are reflected in the fact that not all topics may have rules for the linguistic phenomenon application. For example, in the 4th grade «Mother tongue» textbook [3] themes related to «Parts of speech », «Noun - parts of speech», «Adjectives - parts of speech», «Numbers - parts of speech», «Personal pronouns», «Verb - parts of speech» sections.

Relevant spelling rules using a comma on the "Connection of cohesive parts" subject at the "Sentence" level, punctuation in the subject of "Appeal", in the "Sounds and letters" section, the pronunciation of certain sounds at the end of a word,in «Levels specific to the next division of word group levels - « Noun - parts of speech » section on the topic "Use of nouns with possessive suffixes" etc. is given. Pupils also practice looking for the appropriate rule from 
the topics as they learn to find levels and sections.

Classification is, on the one hand, a term-concept that aims to give pupils a systematic understanding of a linguistic phenomenon, and, on the other hand, a description of the linguistic phenomenon itself (e.g., meaning, pronunciation, spelling, usage of the adverb) based on this term-concept. The term-concept learned later participates as a familiar component in new theoretical knowledge about a new linguistic phenomenon.

As can be seen, while a knowledge range introduces pupils to theoretical concepts, another set of knowledge serves as a basis for talking about linguistic phenomena, and finally moves on to the ability formation to apply the rules expressed through specific knowledge through theoretical observations. It should be noted that the first kind of knowledge provides a basis for understanding the newly studied language phenomena, the correct and complete understanding of the content of the rules. Ultimately, speech development is ensured through the practical application of the knowledge gained.

It turns out that it is necessary to master the terms. For example, when it is said, "Voices consonants at the end of a word become voiceless consonants," pupils can understand the meaning of a rule correctly and completely only if they know the concepts of voiced consonants and voiceless consonants. Observations show that pupils sometimes understand the theoretical knowledge content, but do not know which language phenomenon they are talking about. At this point, theoretical knowledge cannot fully demonstrate its practical significance.

The linguistic term, which is the name of this or that concept, is remembered in its associative connection with linguistic phenomena. If this connection is weak, the term may not recall the concept. In that case, the linguistic term is perceived by readers as an ambiguous word. In order to prevent this, there is a need for terminological $\rightarrow$ conceptual analysis in exercises aimed at strengthening theoretical knowledge.

Exercises that require analysis are also needed to activate the terms in speech. Typically, exercises are performed that break a given word into word groups and ask you to move the words that belong first to one word group and then to another word group. This work type is less effective in mastering terms, as the terms are only spoken once or twice. It is highly effective to read the words given at this point, stating which category each one belongs to, because the terms do not fall out of the language of the readers. Repeated speaking allows them to be activated.

Understanding the differences between language levels and language phenomena represents one of the higher knowledge levels associated with imagining a native language course. This provides a basis for understanding interlevel connections. This means that the knowledge imparted to pupils will not be at the same level. One introduces the language level, another is aware of the linguistic phenomena that fall within the language level, and another is the understanding the differences between several language levels, the general language structure.

\section{Conclusion}

Thus, knowledge of the term-concept, its introduction to a level is an important part of the knowledge of the rule being studied. This thing helps you decide which section of the textbook to look for when you forget a rule about this or that language phenomenon.

\section{References}

1. Mirmakhsudova M. Linguometical bases of use of grammatical terms in improvement of pupils' speech (on the example of native language lessons of 5-7 grades) :diss for cand.ped.scie. -Tashkent, 2004. - 58 pages. $160 \mathrm{p}$.

2. Mother tongue: a textbook for the 3rd grade of general secondary schools / S. Fuzailov, M. Khudoiberganova, Sh. Yuldasheva. - 14th edition. — T .. "Teacher" NMIU, 2016. —152 pages.

3. Native language textbook for the 4th grade of general secondary schools / R. Ikromova. Yuldashevf, D.Shodmonkulova . 8th edition. - Tashkent: "Teacher" NMIU, 2017. - 192 p.

4. Slesareva I.P. Problems of description and teaching of Russian vocabulary. Ed. 2nd corrected. - M.: Russian language, 1990. - 19-20 - $176 \mathrm{p}$. 